condition improved after treatment with amoxycillin, physiotherapy, and blood transfusion. At this time a $10 \%$ reticulocytosis developed; the peripheral lymphocyte numbers including OKT4 reactive cells were extremely low. In view of the considerable risk of opportunistic infection and the steroid myopathy the dose of prednisolone was reduced to $15 \mathrm{mg}$. From that time his condition improved appreciably. No further blood transfusion was required, and in October 1983 the dose of prednisolone was reduced to $10 \mathrm{mg}$. He subsequently remained in remission taking cyclophosphamide $50 \mathrm{mg}$ plus prednisolone $10 \mathrm{mg}$ a day.

\section{Discussion}

Idiopathic acquired pure red cell aplasia is associated with thymoma in about one third to one half of cases. Its occurrence with other autoimmune disorders and reports of successful responses to thymectomy, immunosuppressive drugs, and plasmapheresis $^{3}$ have suggested an immunological basis. In some cases the suppression of erythropoiesis appears to be mediated by humoral agents, thought to be antibodies. Putative antibodies have been shown against erythropoietin and mature erythroblasts. ${ }^{3}$ Recent reports have shown that inhibition of erythropoiesis can be effected by suppressor T lymphocytes. ${ }^{12}$

Monoclonal antibodies are available to identify T cell subsets. ${ }^{4}$ The T8 positive population contains both suppressors and cytotoxic cells. Our patient had an excess of lymphocytes in his bone marrow and high numbers of $\mathrm{T} 8$ positive cells in peripheral blood before treatment. Thymectomy followed by immunosuppression with prednisolone and cyclophosphamide effected a considerable reduction in $\mathrm{T} 8$ positive cells and clinical remission. Although functional studies were not performed, we think it probable that these cells played a part in the suppression of erythropoiesis.

Bacigalupo et al indicated that in severe aplastic anaemia the detection of suppressor $\mathrm{T}$ cells in the bone marrow correlates with successful responses to immunosuppressive regimens. ${ }^{5}$ Our observation would lend support to a similar assertion regarding pure red cell aplasia.

We thank Dr I S Bailey for permission to report this case, and Dr R R Slade and Mr K Jeyasingham for their help with the clinical management.

\section{References}

1 Hoffman R, Kopel S, Hsu SD, Dainiak N, Zanjani ED. T cell chronic lymphocyte leukemia: presence in bone marrow and peripheral blood of cells that suppress

2 Nagasawa T, Abe T, Nakagawa T. Pure red cell aplasia and hypogammaglobulinemia associated with $\mathrm{Tr}$-cell chronic lymphocytic leukemia. Blood

3 Anonymous. Red cell aplasia [Editorial]. Lancet 1982;i:546-7. therapeutic applications. Clin Haematol 1982;11:631-60. Bacigalupo A, Podesta M, Van Lint MT, et al. Severe aplastic anaemia: correlation of in vitro tests with clinical response to immunosuppression in 20 patients. Br $\mathcal{F}$ Haematol $1981 ; 47: 423-33$.

(Accepted 31 August 1984)

\title{
A sensitive immunoradiometric assay for serum thyroid stimulating hormone: a replacement for the thyrotrophin releasing hormone test?
}

\author{
J SETH, H A KELlETT, G CALDWELl, V M SWEETING， G J BECKETT, S M GOW， A D TOFT
}

\begin{abstract}
The value as a thyroid function test of a new, rapid, and highly sensitive immunoradiometric assay for thyroid stimulating hormone (TSH) was assessed in 188 consecutive new patients with suspected hyperthyroidism. The diagnosis was made on clinical grounds and on the basis of serum total triiodothyronine and thyroxine concentrations and the response of TSH to thyrotrophin releasing hormone (TRH) as measured by radioimmunoassay. In all except one patient the basal TSH concentration by immunoradiometric assay predicted the response of TSH by radioimmunoassay to TRH, an undetectable value being recorded in patients with a subnormal
\end{abstract}

\footnotetext{
University Departments of Medicine and Clinical Chemistry, Royal Infirmary, Edinburgh EH3 9YW

J SETH, PHD, MCB, top grade biochemist

H A KELLETT, MRCP, lecturer

G CALDWELL, MRCP, registrar

V M SWEETING, MSC, biochemist

G J BECKETT, PHD, senior lecturer

S M GOW, BSC, biochemist

A D TOFT, MD, FRCP, senior lecture

Correspondence to: Dr A D Toft, Department of Medicine, Royal Infirmary, Edinburgh EH3 9YW.
}

response and a measurable value in those with a normal test result. This clear relation was not observed for basal TSH concentrations as measured by radioimmunoassay. In a series of 39 hospital inpatients with acute or chronic non-thyroidal illness, of whom 11 had low concentrations of total thyroxine or triiodothyronine, or both, basal TSH concentrations were detectable by both radioimmunoassay and immunoradiometric assay in all cases and were associated with normal responses to TRH.

The immunoradiometric assay for TSH, which is commercially available, may therefore obviate the need for the more time consuming TRH test and simplify the approach to thyroid function testing in patients with suspected hyperthyroidism.

\section{Introduction}

Measurement of the basal serum concentration of thyroid stimulating hormone (TSH) is an essential test in the investigation of suspected hypothyroidism. A raised concentration confirms a primary cause of the disease, while a normal or low concentration excludes it or, more rarely, indicates a pituitary or hypothalamic cause. Except in thyrotoxicosis induced by $\mathrm{TSH}$, which is extremely rare, the basal serum TSH concentration is suppressed in hyperthyroidism. These low TSH concentrations, however, are of little diagnostic value as most 
radioimmunoassays for TSH have limited sensitivity (detection limits 1-2 mU/1), so that concentrations are recorded as undetectable not only in hyperthyroid patients but also in some euthyroid patients. Measurement of serum TSH concentrations before and after intravenous administration of thyrotrophin releasing hormone ( $T R H)$ is therefore often required to discriminate between euthyroidism and hyperthyroidism. A normal TSH response excludes a diagnosis of hyperthyroidism, while a subnormal response is consistent with overt or subclinical hyperthyroidism.

The development of a sensitive immunoradiometric assay for TSH (Boots-Celltech Sucrosep TSH IRMA, Boots-Celltech Diagnostics Limited, Slough SL1 4ET, Berkshire) that is claimed to detect TSH concentrations as low as $0.05 \mathrm{mU} / 1$ raised the possibility that the assay might discriminate between basal concentrations in euthyroid and hyperthyroid patients, thereby avoiding the need for a TRH test. We describe our experience in assessing this possibility.

\section{Patients and methods}

We studied 188 new patients consecutively referred to a thyroid clinic with suspected hyperthyroidism. Their mean age was 48 (range 19-81). Thyroid state was assessed clinically by one of us (ADT) and by measurement of serum concentrations of total triiodothyronine, total thyroxine, and TSH (by radioimmunoassay) before and 20 minutes after intravenous administration of $200 \mu \mathrm{g} \mathrm{TRH}$ (TRH test). Basal TSH concentrations were also measured by the immunoradiometric assay, but the results were not used to determine the diagnostic categories of the patients. In 110 patients there was evidence of hyperthyroidism with raised serum concentrations of total triiodothyronine and thyroxine and a subnormal TSH response to TRH. The hyperthyroidism was due to Graves' disease, multinodular goitre, and solitary autonomously functioning thyroid nodule in 87 20 , and three patients respectively. Sixteen patients were considered to have subclinical hyperthyroidism on the basis of normal thyroid hormone concentrations and a subnormal TSH response to TRH. Ten of these patients had a multinodular goitre, one a solitary thyroid nodule that resolved spontaneously, two ophthalmic Graves' disease, and three diffuse thyroid enlargement presumed to represent Graves' disease in remission. Of the remaining 62 euthyroid patients, 13 had a solitary thyroid nodule, 14 a multinodular goitre, and 35 no evidence of thyroid disease. In these 62 patients normal concentrations of total triiodothyronine and thyroxine were associated with a normal TRH test result.

The above thyroid function tests were also performed within 36 hours after admission in 39 patients admitted consecutively as an emergency to a general medical unit with acute or chronic nonthyroidal illness. Their mean age was 61 (range 15-86), and none had clinical evidence or a history of thyroid disease.

After collection of blood the separated serum was stored at $-20^{\circ} \mathrm{C}$ in aliquots for each assay. Serum total triiodothyronine and thyroxine concentrations were measured by double antibody radioimmunoassays, ${ }^{1}$ the normal ranges being $1 \cdot 1-2.8 \mathrm{nmol} / 1(0.7-1.8 \mathrm{ng} / \mathrm{ml})$ and $70-150 \mathrm{nmol} / 1(5 \cdot 4-11 \cdot 7 \mu \mathrm{g} / 100 \mathrm{ml})$ respectively. Serum TSH concentration was measured by the double antibody radioimmunoassay routinely used in the laboratory, ${ }^{2}$ the normal range being from undetectable to $6 \mathrm{mU} / 1$. The assay used a sheep anti-TSH antiserum of good specificity such that there was no interference from follicle stimulating hormone and luteinising hormone at postmenopausal concentrations, or from human chorionic gonadotrophin at the concentrations found in pregnancy.

TSH was also measured by the Boots-Celltech Sucrosep TSH immunoradiometric assay using the protocol enclosed with the kit. Both the radioimmunoassay and the immunoradiometric assay were calibrated in terms of the TSH International Reference Preparation 68/38. The immunoradiometric assay had a substantially lower limit of detection, wider working range, and better within assay precision than the radioimmunoassay (table I). Although our radioimmunoassay has a lower limit of detection than many others, this is achieved only at the expense of a relatively long assay time. There was an excellent correlation between TSH concentrations measured by radioimmunoassay and by immunoradiometric assay in a separate series of 108 patients in whom values lay between 0.9 and $130 \mathrm{mU} / \mathrm{l}$ $(\mathbf{r}-0.99 ; \mathrm{p}<0.001)$. There was no evidence of interference in the immunoradiometric assay from follicle stimulating hormone and luteinising hormone at postmenopausal concentrations, as shown by basal TSH concentrations that were consistently undetectable in both premenopausal and postmenopausal patients with thyrotoxicosis. This was in agreement with the kit manufacturer's claim of cross reactivities of less than $0.002 \%$ for both follicle stimulating hormone and luteinising hormone.

TABLE I-Comparison of laboratory performance of radioimmunoassay and immunoradiometric assay for TSH (mean values for 10 assays)

\begin{tabular}{lcc}
\hline & Radioimmunoassay & $\begin{array}{c}\text { Immunoradiometric } \\
\text { assay }\end{array}$ \\
\hline $\begin{array}{l}\text { Detection limit (mU/1)* } \\
\text { Range (mU } / 1) \text { for a } 10 \% \text { coefficient } \\
\text { of variation }\end{array}$ & $0 \cdot 9$ & 0.07 \\
$\begin{array}{l}\text { Within assay precision (coefficient } \\
\text { of variation) }+\end{array}$ & $1 \cdot 0-10 \cdot 0$ & $0 \cdot 5-240$ \\
$\begin{array}{l}\text { Between assay precision (coefficient } \\
\text { of variation) }+\end{array}$ & $5 \%$ & $3 \%$ \\
Time required (days) & $7 \%$ & $9 \%$ \\
\hline
\end{tabular}

${ }^{*}$ Minimum concentration that can be distinguished from zero at $95 \%$ confidence level. $\ddagger$ Mean value for serum pools $3 \cdot 0,7 \cdot 1,21 \cdot 0$, and $52 \cdot 0 \mathrm{mU} / 1$.

\section{Results}

The figure shows basal TSH concentrations measured by both radioimmunoassay and immunoradiometric assay in the patients attending the clinic and in those with non-thyroidal illness. Among the 110 patients with hyperthyroidism $\mathrm{TSH}$ was undetectable by radioimmunoassay (less than $0.9 \mathrm{mU} / \mathrm{l}$ ) in 101 , and in the nine remaining patients concentrations of $1.0-1.7 \mathrm{mU} / 1$ were recorded, which overlapped the euthyroid range. In contrast, the more sensitive immunoradiometric assay recorded undetectable concentrations (less than $0.07 \mathrm{mU} / \mathrm{l})$ in all patients. Among the 16 patients with subclinical hyperthyroidism radioimmunoassay recorded undetectable TSH concentrations in 13 and concentrations of $1.1,1.0$, and $1.0 \mathrm{mU} / 1$ in three; whereas immunoradiometric assay recorded undetectable concentrations in all but one patient, in whom a value of $0.14 \mathrm{mU} / 1$ was recorded (see Discussion). TSH concentrations were detectable in 60 of the 62 euthyroid patients and in all 39 with non-thyroidal illness when measured by radioimmunoassay, and in every patient in these two groups when measured by immunoradiometric assay.

Comparison of basal TSH concentrations with the response of TSH to TRH measured by radioimmunoassay (table II) showed that all but one patient with a detectable basal TSH concentration on immunoradiometric assay yielded a normal result to the TRH test.

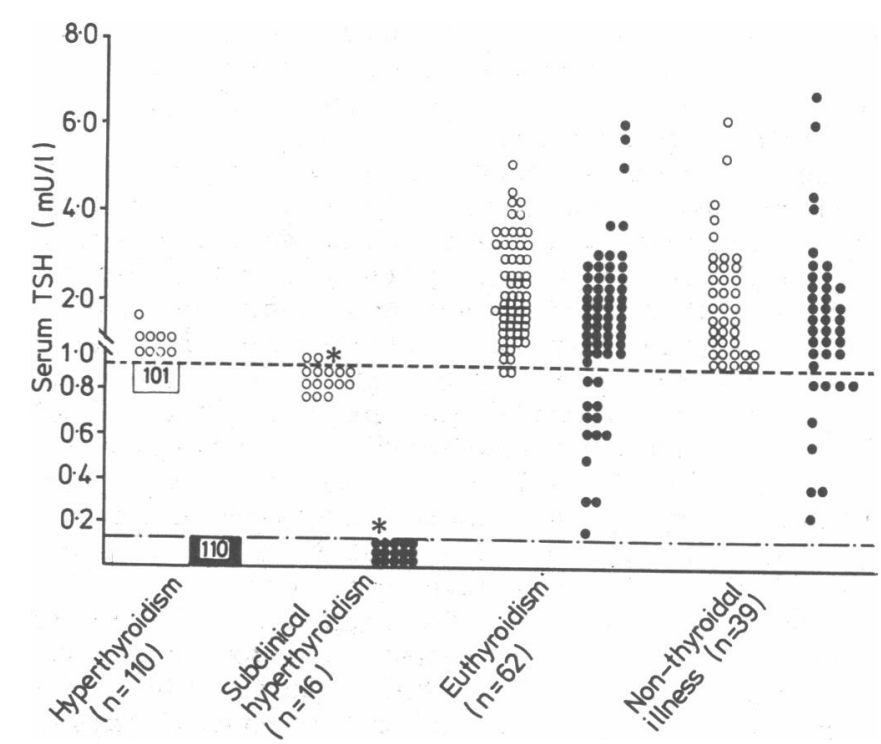

Serum TSH concentrations measured by radioimmunoassay (O) and by immunoradiometric assay (O) in patients with thyroid disease and patients with non-thyroidal illness. Broken lines indicate limits of detection for radioimmunoassay $(0.9 \mathrm{mU} / \mathrm{l})$ and immunoradiometric assay $(0.07 \mathrm{mU} / \mathrm{l})$. The asterisk indicates the single patient in whom the immunoradiometric assay did not predict the result of the TRH test. 
Conversely, in all patients with an undetectable basal TSH concentration on immunoradiometric assay there was a subnormal response of TSH to TRH on radioimmunoassay. The same close relation was not seen, however, between basal TSH concentrations measured by radioimmunoassay and the result of the TRH test. Thus two euthyroid patients with undetectable TSH concentrations on radioimmunoassay gave normal responses to $\mathrm{TRH}$, and nine

TABLE II-Relation between basal serum TSH and response of TSH to TRH (figures show numbers of patients in each category)

\begin{tabular}{lcccccc}
\hline & \multicolumn{4}{c}{ Basal TSH } \\
\cline { 2 - 3 } $\begin{array}{c}\text { Response to } \\
\text { TRH }\end{array}$ & \multicolumn{2}{c}{ Radioimmunoassay } & & \multicolumn{2}{c}{ Immunoradiometric assay } \\
\cline { 2 - 3 } \cline { 5 - 6 } & Detectable & Undetectable & & Detectable & Undetectable \\
\hline Normal* $_{\text {Subnormal }}^{60}$ & 12 & 2 & & 62 & 0 \\
& 12 & 114 & & 1 & 125
\end{tabular}

*TSH concentration (by radioimmunoassay) at 20 minutes of $1.0 \mathrm{mU} / 1$ or more above basal value.

hyperthyroid patients and three patients with subclinical hyperthyroidism with detectable TSH concentrations on radioimmunoassay showed a subnormal response to TRH.

In all 39 patients with non-thyroidal illness there were detectable TSH concentrations on radioimmunoassay and immunoradiometric assay associated with normal TRH test results, despite low concentrations of total thyroxine or triiodothyronine, or both, in 11 .

\section{Discussion}

The important advantages of the immunoradiometric assay compared with the radioimmunoassay-namely, higher specificity, lower limit of detection, wider working range, and speed of analysis-are a consequence of the fundamentally different principles on which the assays are based. The BootsCelltech Sucrosep immunoradiometric assay uses a combination of two monoclonal antibodies, each of which is specific for a different epitope on the TSH molecule. One antibody is bound to a solid matrix while the other is radiolabelled. Simultaneous binding of both antibodies to TSH results in the formation of a radiolabelled insoluble "sandwich," the concentration of which is directly related to the amount of TSH in the sample. The concentration of the insoluble sandwich is indicated by the amount of radiolabel in the insoluble form. The specificity derives from the requirement for binding by two distinctly separate antibodies, while the other advantages of low limit of detection, wide working range, and speed derive from the use of excess reagents in the assay.

Although the immunoradiometric assay is superior to the radioimmunoassay from the laboratory point of view, it is important to assess whether these analytical advantages provide real improvements for the investigation of thyroid disease. Our results show that TSH concentrations as measured by the immunoradiometric assay can reliably predict the response to TRH and thereby simplify the assessment of thyroid function in patients with suspected hyperthyroidism. Whereas basal TSH concentration as measured by radioimmunoassay predicted the response of TSH to TRH in 175 out of 188 patients, when measured by immunoradiometric assay it predicted the response in. 187 of the 188 patients. The exception was a patient who presented with a solitary thyroid nodule that regressed spontaneously after three months, suggesting a diagnosis of haemorrhage into a cyst or adenoma. At presentation total triiodothyronine and thyroxine concentrations were in the middle of their respective normal ranges at $1.6 \mathrm{nmol} / 1(1.0 \mathrm{ng} / \mathrm{ml})$ and $91 \mathrm{nmol} / 1(7 \cdot 1 \mu \mathrm{g} / 100 \mathrm{ml})$. The basal TSH concentration on radioimmunoassay was $1.0 \mathrm{mU} / 1$ and showed a marginally subnormal increase to $1.9 \mathrm{mU} / \mathrm{l}$ after administration of TRH. Such a result was not expected on clinical grounds, and the basal TSH concentration of $0 \cdot 14 \mathrm{mU} / 1$ as measured by immuno- radiometric assay was more consistent with the probable diagnosis.

Our findings suggest that it may no longer be necessary to perform the time consuming TRH test in patients referred with possible hyperthyroidism and that clinical assessment and measurement of total or free triiodothyronine and thyroxine concentrations and of basal TSH concentrations by immunoradiometric assay are sufficient. Like a subnormal response of $\mathrm{TSH}$ (on radioimmunoassay) to $\mathrm{TRH}$, an undetectable $\mathrm{TSH}$ concentration on immunoradiometric assay would be consistent with a diagnosis of hyperthyroidism but would also be recorded, as in this series, in patients with subclinical hyperthyroidism associated with multinodular goitre, autonomous solitary nodule, and ophthalmic Graves' disease. ${ }^{3}$ Undetectable concentrations are also likely to be recorded in some patients receiving replacement treatment with thyroxine and in the presence of normal or even low concentrations of thyroid hormones in the early weeks after treatment of hyperthyroidism due to the delayed recovery of the previously suppressed pituitary thyrotrophs. ${ }^{4} \mathrm{~A}$ detectable result on immunoradiometric assay would exclude hyperthyroidism. It is important to consider the possible effects of non-thyroidal illness on immunoradiometric assay of basal $\mathrm{TSH}$ concentrations. It is well recognised that low thyroid hormone concentrations and a reduced serum TSH response to TRH may occur in patients with non-thyroidal illness, such as pneumonia, myocardial infarction, or renal failure, ${ }^{5}$ and such abnormalities are a common cause of difficulty in interpreting test results in hospital patients. In all 39 cases in this series, however, detectable basal TSH concentrations on immunoradiometric assay correctly predicted a euthyroid state as defined by a normal response of TSH to TRH.

Immunoradiometric assays are now increasingly being used to measure peptide hormones. Although these new methods are known to have several analytical advantages over radioimmunoassay, we believe that this study is the first to show an appreciable clinical benefit from the new generation of immunoassay technology.

\section{References}

1 Ratcliffe WA, Challand GS, Ratcliffe JG. A critical evaluation of separation methods in radioimmunoassays for total triiodothyronine and thyroxine in unextracted human serum. Ann Clin Biochem 1974;11:224-9.

2 Irvine WJ, Toft AD, Hunter WM, Kirknam KE. An assessment of plasma TSH radioimmunoassay and of TSH stimulation test in the diagnosis of 100 con secutive patients with suspected hypothyroidism. Clin Endocrinol 1973;2:135-9 amberg B-A, Gordin A. Abnormalities of thyrotrophin secretion and clinica implications of the thyrotrophin releasing hormone stimulation test. Ann Clin Res Toft AD, Irvine WJ, Sinclair I, McIntosh D, Seth J, Cameron EHD. Thyroid Lim VS, Fang VS, Katz AI, Refetoff S. Thyroid dysfunction in chronic ren failure. F Clin Invest 1977;60:522-34.

(Accepted 6 September 1984)

\section{ONE HUNDRED YEARS AGO}

The class of idiots commonly known as "Shah Dowla's mice," from the peculiar mouse-like conformation of their cranium, have their headquarters at a shrine in the Gujerat district of the Punjab. Their appearance is very characteristic-projecting mouth, extremely low forehead, and cranium long drawn out and tapering to the vertex. It is generally believed that this malformation is produced by forcible moulding or compression of the head in infancy. In the Punjab Lunatic Asylum Report for 1883, Dr. Gray of Lahore gives particulars of a case which leads him to believe that the malformation is congenital. And Dr. Simpson, the Surgeon-General, commenting on the subject, states that, as far as he had been able to gather from inquiries made at Gujerat and elsewhere, the statement that their heads have been forcibly moulded or compressed is quite devoid of foundation. (British Medical Fournal 1884 ;ii :875.) 